\title{
La seguridad en la aviación depende de los factores humanos
}

\section{Esperanza Lozano Alvernia*}

\section{Resúmen}

En este articulo se hace un abordaje sencillo de lo que significan los factores humanos para la seguridad en la aviación visto desde la calidad integral, de ahí que se hace una reflexión de lo que implica la calidad en las instituciones para partir de este concepto y desarrollar los aspectos de los factores humanos, de las disciplinas que orientan el estudio de los factores humanos, y el entrenamiento que debe recibir la tripulación de vuelo según la $\mathrm{OACl}$

Palabras claves: factor humano, calidad, incidente, accidente, disciplinas.

\section{Abstract}

This article makes a simple approach to what human factors mean in aviation safety from an integral point of view, causing the need to make a reflection on institutional quality in different aspects of human factors, the disciplines that orient the study of human factors, and the training that flight crews must receive according to the ICAO.

Key words: human factor, quality, incident, accident, disciplines.

Para que una organización funcione independientemente del sector productivo en el que se encuentre deberá estar certificada para su reconocimiento local e internacional y transformar sus procedimientos a través de los paradigmas de calidad.
Se habla hoy de calidad de los procesos, calidad en los servicios al cliente, calidad en todas las actuaciones de las empresas para optimizar procesos, resultados y también se invierten grandes recursos en el talento humano, ya que si no se capacita, entrena y se desarrollan nuevas habilidades y destrezas, se corre con el riesgo de no lograr el desarrollo y la implementación de una calidad integral. Por tal razón, el sector aeronáutico no puede escapar a los procesos de certificación de los sistemas y subsistemas para competir en la aviación comercial y de los diferentes estados, partiendo de la premisa de que el transporte aéreo es uno de los que representa mayor seguridad para el usuario y es uno de los aspectos más importantes dentro de la estructura aeronáutica. De ahi que la seguridad en la aviación "es el objetivo más importante de la organización de aviación civil internacional ${ }^{\prime \prime}$. Es por esto que es necesario abordar los conceptos del factor humano, ya que tiene incidencia en los accidentes e incidentes del transporte aéreo, "errores de la tripulación, de los controladores, de mantenimiento, de despacho, aumentan las cifras de los accidentes de aviación que se atribuyen a errores humanos ${ }^{\prime \prime 2}$.

Si la seguridad aérea depende en un alto porcentaje del factor humano y su responsabilidad se ve reflejada en evitar accidentes e incidentes entonces, es necesario trabajar con mayor profundidad y creatividad en el desempeño laboral de los pilotos vistos como sujetos complejos que se relacionan con máquinas, equipos y otros artefactos, de ahi que se deben estudiar los factores hu-

\footnotetext{
* Comunicadora Social y Periodista. Universidad de La Sabana. Magister en Literatura Hispanoamaericana, Magister en Docencia Universitaria . Asesora de Investigación, Instituto Militar Aeronáutico.

'CAUDIVILLA NUÑEZ, Paloma, López Pérez Raquel, Ortiz Garcia Pedro Javier y Pérez Sastre José Maria. Factores Humanos en la Aviación. Curso JAR-FCL para pilotos de transporte de líneas aéreas, Editado por American FLYERS España.2000. Păg. 9

Ibid. Pág. 10
} 


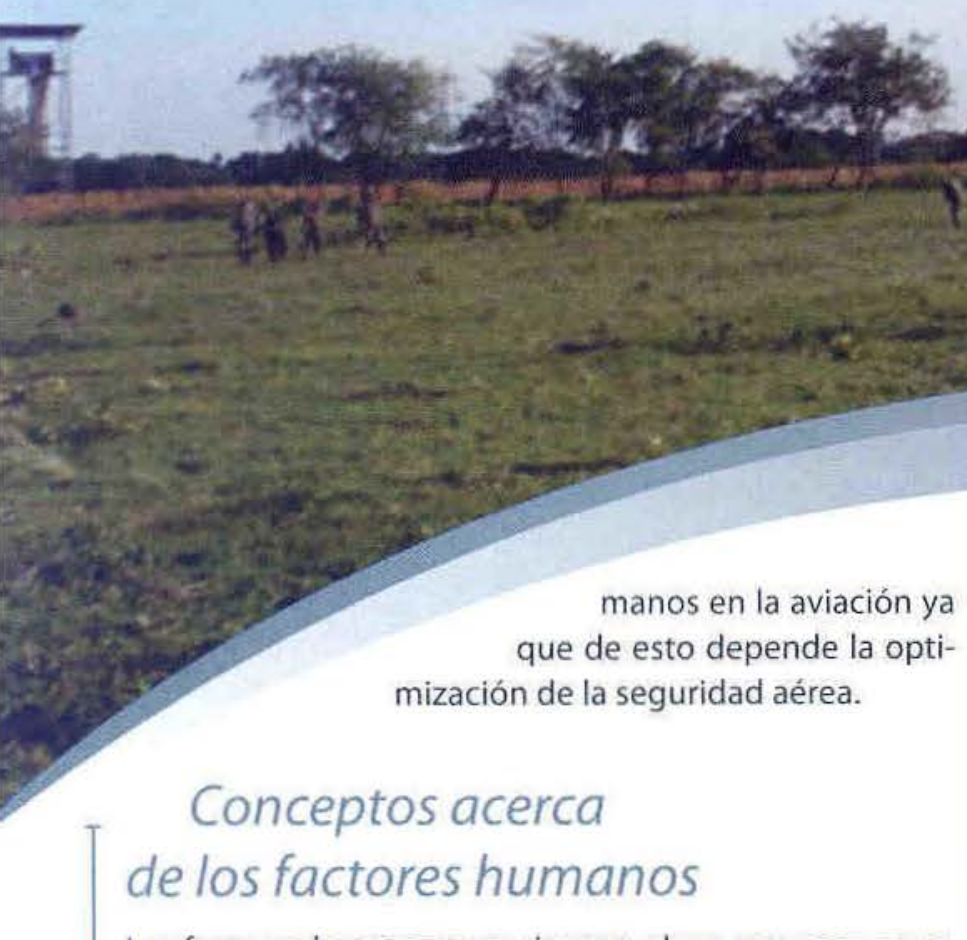

Los factores humanos conciernen a las personas y se refiere a la relación de éstas en los ambientes de trabajo y a su relación con las máquinas, equipos, procedimientos y otras personas del sistema. Los factores humanos trabajan por alcanzar un comportamiento óptimo de las personas mediante la aplicación sistemática de las ciencias humanas cuyo objetivo es la seguridad y la eficacia. Una correcta combinación entre el hombre y la máquina deberá dar respuesta a los siguientes indicadores:

- Eficiencia: permite obtener resultados sin dificultad o esfuerzo excesivo por parte del operador.

- Seguridad: minimización de los riesgos.

- Comodidad y aceptabilidad: adaptación y flexibilidad en el desempeño laboral.

El elemento humano es la parte más flexible y adapta- ble del sistema aeronáutico; siendo el más vulnerable a las condiciones externas que pueden modificar el comportamiento en forma negativa "... ninguna persona puede desempeñar su trabajo perfectamente en todo momento" ${ }^{\prime \prime}$. Por lo tanto, es importante reconocer que se puede fallar.

Los factores humanos se ocupan de diversos elementos del sistema aeronáutico que incluye: comportamiento y desempeño humano, toma de decisiones, diseño de mandos y presentaciones, ergonomía de cabina, comunicaciones, mapas, cartas y documentación; así como el perfeccionamiento y formación del personal.

\section{Disciplinas que orientan el estudio del factor humano}

Los factores humanos exigen un abordaje multidisciplinario por su objeto de estudio, por ejemplo, se puede estudiar desde la ingeniería, psicología, fisiología, medicina, sociología y antropometría.

- Psicología: permite comprender cómo se toman las decisiones.

- Fisiologia: consiste en la observación del cambio de las 
sensaciones que ocurren durante el vuelo.

- Antropometría y Biomecánica: analiza las medidas y movimientos del cuerpo en una cabina de vuelo.

- Medicina: previene las enfermedades que pueden impactar a un piloto.

Las anteriores disciplinas permiten el estudio de los factores humanos para comprender sus actuaciones y los momentos en que alguna alteración en su comportamiento pueden afectar el desempeño causando una falla en el sistema y como consecuencia causando un accidente o incidente.

\section{Entrenamientos en los factores humanos según la OACI}

La OACI reconoce que los problemas en cabina se refieren a la toma de decisiones deficientes, comunicaciones ineficaces, liderazgo inadecuado y mala gestión de los recursos disponibles, por lo que publicó en 1989 las circulares 216 -AN/131 "Compendio sobre factores humanos No1: conceptos fundamentales" y 317-AN/132 sobre "Compendio de factores humanos No. 2 referente a la institución de la tripulación de vuelo" ${ }^{\prime 4}$. Propuso los niveles de pericia necesarios para cualquier organización de aviación civil.

- Nivel 1: todo el personal comprende el comportamiento, las capacidades y limitaciones del ser humano.

- Nivel 2: revisiones que ocupan funciones de supervisión, inspección e instrucción.

- Nivel 3: especialista interno, las compañías aéreas deberán contar con uno o varios para las actividades de vuelo.

- Nivel 4: consultor en factores humanos, deberá tener conocimientos en psicología con orientación al estudio de los factores humanos.

\section{Conceptos y aptitudes que los pilotos deben adquirir:}

- Estandarización del lenguaje.

- Concepto de sinergia.

- Trabajo en equipo.

- Competencia para el vuelo.

- Impacto del ambiente (control tránsito aéreo).

- Identificación de recursos.

- Identificación de prioridades.

- Características del comportamiento humano.

- Identificación de normas y procedimientos.

\section{Aptitudes:}

- Comunicaciones y aptitudes interpersonales.

- Conciencia de la situación.

- Solución de problemas: toma de decisiones.

- Dirección y control.

- Control de la tensión.

- Revisión situación.

Finalmente, aunque ya se ha venido trabajando y aplicando la metodología del CRM, las compañías de aviación deberán cada día trabajar por el mejoramiento continuo del factor humano para gestionar los errores, minimizar y prevenir los incidentes y accidentes generando una cultura de seguridad con calidad.

\section{Bibliografia}

OACl. (Organización Aviación Civil Internacional). Información médica para pilotos. Manual de Medicina Aeronáutica parte V, capitulo 3. doe 8954-AN/895.

ERNISTING, JKING P. Aviation Medicine. Balterworths $2^{2}$ edición. London $1993^{\circ}$ edición. CASTILLO, J. J. Ergonomia, conceptos y métodós. Ed. Complutense. 1999. 